\title{
Microscopy techniques for determining water-cement (w/c) ratio in hardened concrete: a round-robin assessment
}

\author{
H. S. Wong $(\mathbb{D} \cdot$ A. B. Poole $\cdot$ B. Wells $\cdot$ M. Eden $\cdot$ R. Barnes $\cdot$ J. Ferrari $\cdot$ \\ R. Fox • M. H. N. Yio • O. Copuroglu • G. Guðmundsson • R. Hardie • \\ U. H. Jakobsen · K. Makoubi · A. Mitchinson · P. Raybould · J. Strongman • \\ N. R. Buenfeld
}

Received: 23 September 2019/Accepted: 11 February 2020/Published online: 17 February 2020

(C) The Author(s) 2020

\begin{abstract}
Water to cement (w/c) ratio is usually the most important parameter specified in concrete design and is sometimes the subject of dispute when a shortfall in concrete strength or durability is an issue. However, determination of $\mathrm{w} / \mathrm{c}$ ratio in hardened concrete by testing is very difficult once the concrete has set. This paper presents the results from an interlaboratory round-robin study organised by the Applied Petrography Group to evaluate and compare microscopy methods for measuring $\mathrm{w} / \mathrm{c}$ ratio in hardened
\end{abstract}

H. S. Wong $(\varangle) \cdot$ M. H. N. Yio · N. R. Buenfeld Department of Civil and Environmental Engineering, Imperial College London, London SW7 2AZ, UK e-mail: hong.wong@imperial.ac.uk

A. B. Poole · R. Fox

Applied Petrography Group, The Geological Society, London W1V 0JU, UK

B. Wells

Conwy Valley Systems Ltd., Conwy LL31 9BW, UK

M. Eden

Geomaterials Research Services, Sandberg LLP,

London SW4 7TD, UK

R. Barnes

The Concrete Society, Camberley, Surrey GU17 9AB, UK

J. Ferrari

RSK (Environment) Ltd, Hertfordshire HP3 9RT, UK concrete. Five concrete prisms with w/c ratios ranging from 0.35 to 0.55 , but otherwise identical in mix design were prepared independently and distributed to 11 participating petrographic laboratories across Europe. Participants used a range of methods routine to their laboratory and these are broadly divided into visual assessment, measurement of fluorescent intensity and quantitative backscattered electron microscopy. Some participants determined w/c ratio using more than one method or operator. Consequently, 100

O. Copuroglu

Faculty of Civil Engineering and Geosciences, TU Delft, Delft, The Netherlands

G. Guðmundsson

Mannvit, Urðarhvarf 6, Kópavogur, Iceland

R. Hardie

Heath and Hardie Geosciences, Dundee DD4 7BW, UK

U. H. Jakobsen

Danish Technological Institute, 2630 Taastrup, Denmark

K. Makoubi

Petroclays Materials Ltd., Essex IG11 7QX, UK

A. Mitchinson

SLR Consulting, Dundrum 14N4Y7, Ireland

P. Raybould

Enterprise Petrography, Staffordshire WS12 OQU, UK

J. Strongman

Petrolab Ltd., Redruth, Cornwall TR15 3AE, UK 
individual w/c ratio determinations were collected, representing the largest study of its type ever undertaken. The majority $(81 \%)$ of the results are accurate to within \pm 0.1 of the target mix w/c ratios, $58 \%$ come to within \pm 0.05 and $37 \%$ are within \pm 0.025 . The study shows that microscopy-based methods are more accurate and reliable compared to the BS 1881-124 physicochemical method for determining w/c ratio. The practical significance, potential sources of errors and limitations are discussed with the view to inform future applications.

Keywords Water/cement ratio - Fluorescence microscopy $\cdot$ Backscattered electron microscopy . Image analysis $\cdot$ Petrography $\cdot$ Microstructure

\section{Introduction}

Water-to-cement $(\mathrm{w} / \mathrm{c})$ ratio is a critical parameter that controls the performance of hardened concrete and other cement-based materials. A high w/c ratio can lead to excessive porosity, low strength and inadequate durability. A low w/c ratio can also cause excessive voidage from poor compaction and microcracking induced by autogenous shrinkage. As such, w/c ratio is an important design parameter and key to concrete specification. The ability to determine w/c ratio retrospectively is desirable in many situations e.g. for quality control, condition assessment and forensic investigation of failure or suspected noncompliance.

But once concrete has set, it is very difficult to assess the exact amounts of water and cement used in the mix, and hence the original $\mathrm{w} / \mathrm{c}$ ratio. A frequently applied method is the physicochemical method of BS 1881-124 [1], which estimates water content from measurements of capillary water and chemically bound water, and the cement content from partial chemical analysis of soluble $\mathrm{CaO}$ and $\mathrm{SiO}_{2}$. However, this method is prone to errors caused by absorption into voidage, cracks and porous aggregates, and inaccuracies in cement measurement [2-4]. A recent precision trial by the UK Concrete Society found large reproducibility errors of \pm 0.28 on a typical w/c value of 0.50 [3]. The study concluded that the method is not sufficiently accurate to provide useful data and suggests that it should not be relied upon for compliance testing or forensic engineering [5-7].

Petrographic optical microscopy methods such as those described in ASTM C856 [8], NT 361-1999 [9], APG SR2 [10] and BS 1881-211 [11] are based on indicators of apparent w/c ratio such as variation in capillary porosity, residual unreacted cement and portlandite content [2-4, 8-13]. Assessment of capillary porosity is a key feature and this is estimated indirectly by impregnating the sample with epoxy resin containing fluorescein dye and subsequent examination under UV light $[14,15]$. In the absence of other influencing factors, the observed fluorescence intensity is an indirect measure of intruded resin and capillary porosity. The w/c ratio of the unknown concrete is then estimated by visually comparing its fluorescence intensity to a set of reference concretes of similar type made with known w/c ratios $[4,9,10,16]$. Fluorescence intensity can also be quantified using image analysis [17-20], which is potentially more sensitive and precise than visual comparison.

An alternative method using field-emission scanning electron microscopy (SEM) in the backscattered electron (BSE) mode has been developed [21-23]. The superior resolution of SEM-BSE coupled with image analysis allows direct measurement of the capillary porosity, air voids, hydration products and residual unreacted cement. The measured phase assemblage is then used to back-calculate the original water and cement contents prior to hydration. The main advantage of this approach is that it can be applied to concretes of unknown history without the need for reference samples.

Microscopy techniques are used in many commercial and research laboratories concerned with petrographic examination of cement-based materials. However, very little independent research has been carried out to evaluate their precision and accuracy for assessing w/c ratio. The validity of some of these techniques has been questioned [24-27]. Therefore, an industry-wide study to assess these techniques is very much needed. In late 2015, the Applied Petrography Group (APG) an affiliate to the Engineering Group of the Geological Society of London, began discussions concerning the organisation of an inter-laboratory study to address this need. The main objectives of the study are to: (a) investigate the validity of optical fluorescence microscopy, visual assessment and backscattered electron microscopy for determining 
Table 1 Mix proportions at saturated-surface dry condition adjusted for yield

\begin{tabular}{lllllll}
\hline $\begin{array}{l}\text { Mix } \\
\text { ID }\end{array}$ & W/c & $\begin{array}{l}\text { Free water }(\mathrm{kg} / \\
\left.\mathrm{m}^{3}\right)\end{array}$ & $\begin{array}{l}\text { CEM I }(\mathrm{kg} / \\
\left.\mathrm{m}^{3}\right)\end{array}$ & $\begin{array}{l}\text { Fine aggregate }(\mathrm{kg} / \\
\left.\mathrm{m}^{3}\right)\end{array}$ & $\begin{array}{l}\text { Coarse aggregate }(\mathrm{kg} / \\
\left.\mathrm{m}^{3}\right)\end{array}$ & $\begin{array}{l}\text { Theoretical density }(\mathrm{kg} / \\
\left.\mathrm{m}^{3}\right)\end{array}$ \\
\hline A & 0.35 & 157 & 450 & 898 & 898 & 2403 \\
$\mathrm{C}$ & 0.40 & 176 & 440 & 876 & 876 & 2369 \\
$\mathrm{E}$ & 0.45 & 192 & 428 & 853 & 853 & 2325 \\
$\mathrm{~B}$ & 0.50 & 207 & 414 & 825 & 825 & 2271 \\
$\mathrm{D}$ & 0.55 & 230 & 417 & 831 & 831 & 2307 \\
\hline
\end{tabular}

w/c ratio in hardened concretes; (b) examine the precision of the results obtained for a series of concretes within a normal range of w/c ratios; and (c) compare the results obtained by participating laboratories and to the BS 1881-124 method.

\section{Round-robin organisation and participants}

A steering committee was set up by the APG to organise and oversee the round-robin tests, and report on its findings. This was chaired by Mr Richard Fox and Dr Alan Poole was the Secretary. They were empowered to seek expert advice as necessary, and have received numerous comments from APG members on the round-robin exercise. In October 2016, the committee agreed after wide consultation that five test concrete mixes should be prepared for the trial. These were simple concrete mixes containing no chemical admixtures or mineral additions. The same mix design was used throughout with the only variable being the w/c ratio. Test specimens were prepared by the Tarmac Technical Centre at Lutterworth, UK in May 2017 and distributed to participants for examination with their in-house microscopy methods.

Initially contact was made with 29 laboratories across the UK and Europe to enquire whether they would be interested in participating in this round-robin study. Eleven laboratories agreed to participate and specimens were dispatched to the following:

- Dr Oguzhan Copuroglu, Delft University (Netherlands).

- Mr Mike Eden, Sandberg (UK).

- Mr James Ferrari, RSK Ltd. (UK).

- Dr Gisli Guðmundsson, Mannvit (Iceland).

- Dr Rachel Hardie, Heath \& Hardie Geosciences (UK).
- Dr Ulla Hjorth Jakobsen, Danish Technological Institute (Denmark).

- Mr Kiket Makoubi, Petroclays Materials Ltd. (UK).

- Ms Alice Mitchinson, SLR Consulting (Ireland).

- Mr Phil Raybould, Enterprise Petrography (UK).

- Mr James Strongman, Petrolab Ltd. (UK).

- Dr Hong Wong, Imperial College London(UK).

In order to maintain confidentiality, each laboratory was allotted a unique reference number. Participants were asked to report their findings and methodology on a pro-forma drafted by the Secretary. The exact w/c ratios of the specimens were known only to the Chair and Secretary throughout the trial.

\section{Methodology}

\subsection{Materials and mix design}

Five concrete mixes with w/c ratios ranging from 0.35 to 0.55 were prepared (Table 1). Mixes were proportioned to have sufficient workability to be cast without excessive voidage or honeycombing at w/c 0.35, but sufficient cohesion and segregation resistance at w/c 0.55 . The mix design was based on absolute volume and standardised with the main variable being w/c ratio. Preliminary details and requirements of the mix design were discussed by APG members, but the final design was developed by the Chair and Secretary, in close consultation with Mr Michael Thomas (Technical Optimisation Manager, Tarmac Ready Mix Technical Centre, Lutterworth) who carried out trial mixes to ensure feasibility. It is worth emphasising that the w/c ratios were not disclosed to participants.

CEM I $52.5 \mathrm{~N}$ Portland cement supplied by Tarmac/CRH, Tunstead was used. The average Bogue 
composition was $73.3 \% \mathrm{C} 3 \mathrm{~A}, 11.5 \% \mathrm{C} 2 \mathrm{~S}, 7.3 \% \mathrm{C} 3 \mathrm{~A}$ and $9.8 \% \mathrm{C} 4 \mathrm{AF}$. Coarse aggregate was Tunstead crushed limestone $(4 / 10 \mathrm{~mm})$ and fine aggregate was Alrewas natural quartz sand $(0 / 4 \mathrm{~mm})$. The contents of water and cement were varied to achieve the target w/c ratio. Aggregate to cement ratio was kept constant at 3.99 for all mixes. Aggregates were oven-dried and their water absorption $(1.5 \%$ for coarse and $0.1 \%$ for fine aggregate) was considered in the mix design. Water was added to bring the oven-dried aggregates to saturated and surface dry state.

\subsection{Specimen preparation}

Specimen preparation was carried out in the laboratories of Tarmac Ltd., Lutterworth, observed by Dr Ian Heritage (Senior Advisory Engineer, The Concrete Society) and Dr Alan Poole (APG Secretary). Batching was done by mass using a calibrated balance. Oven dried aggregates were cooled to ambient temperature prior to batching. Mixing was carried out using a $5 \mathrm{~L}$ capacity forced action "Hobart" mixer.

Aggregates were added to the mixing bowl and uniformly distributed. Two-thirds of the mix water was then added and the bowl covered with damp cloth was allowed to stand for $10 \mathrm{~min}$. Mixing was carried out at low speed for $15 \mathrm{~s}$. Cement was added followed by the remaining one-third of the water. This was mixed at low speed for $30 \mathrm{~s}$ and then at medium speed for a further $5 \mathrm{~min}$. Subsequently, the mixer was stopped and any unmixed material from the sides and base of the bowl was scraped and incorporated into the mixture. Mixing was continued for another minute and visually checked for homogeneity.

Five prisms with nominal dimensions of $75 \times 75 \times 300 \mathrm{~mm}$ were cast in steel moulds from each concrete. Each mould was filled and compacted in two layers. The amount of compaction was varied according to w/c ratio to achieve well-compacted concrete without excessive segregation. The w/c 0.35 and 0.40 mixes were compacted with vibrating table for $90 \mathrm{~s}$ per layer and $60 \mathrm{~s}$ per layer respectively, until no air bubbles escaped. The w/c 0.45 and 0.50 mixes were hand tamped, while the w/c 0.55 mix was lightly tapped with a rubber mallet at each fill. The compacted prisms were labelled and covered in polythene membrane for the first $24 \mathrm{~h}$, then demoulded, photographed (Fig. 1) and transferred immediately to a humidity cabinet for curing at
$20{ }^{\circ} \mathrm{C}, 80 \% \mathrm{RH}$. This was carried out one prism at a time to eliminate any possibility of miss-identification. The prisms were labelled A, B, C, D and E, but the identifications were randomised with respect to their w/c ratios (Table 1).

After 28-day curing, the prisms were sealed in polythene bags and plastic containers, and dispatched to Sandberg Clapham laboratory where each prism was sliced transversely with diamond saw into 14 subspecimens of $17 \mathrm{~mm}$ thickness. The first $5 \mathrm{~mm}$ from the ends of each prism was discarded. The slices were marked with their mix ID and numbered 1-14, then wrapped in cling film and sealed individually in polythene bags to prevent drying and carbonation. The sub-specimens were then dispatched to Imperial College London (July 2017), where they were imaged (back and front) with a flatbed scanner, sealed immediately and repacked into 14 sets and distributed to participating laboratories. Figure 1 shows example cross-section scans of the sub-specimens.

\subsection{Microscopy techniques}

Participants were required to prepare their sub-specimens for microscopy and determine the w/c ratio using their routine in-house methodology. All participants prepared polished thin-sections or blocks impregnated with fluorescein-dyed resin. These were examined either with optical petrographic microscopy or with scanning electron microscopy. However, there were variations in the resin, fluorescein dye, specimen size, equipment, number of images and magnification adopted, as would be expected. Details of the methods used by each participant are summarised in Table 2 .

The microscopy methods employed fall into four main groups:

(a) Visual assessment of cement paste characteristics (VA).

(b) Visual comparison of fluorescent intensity using fluorescence microscopy (FM-V).

(c) Quantitative assessment of fluorescent intensity using fluorescence microscopy (FM-Q).

(d) Quantitative assessment of unreacted cement, hydration products and capillary porosity using backscattered electron microscopy (BSE).

Details of each method are presented in Table 3. All except Lab 11 used optical fluorescence 


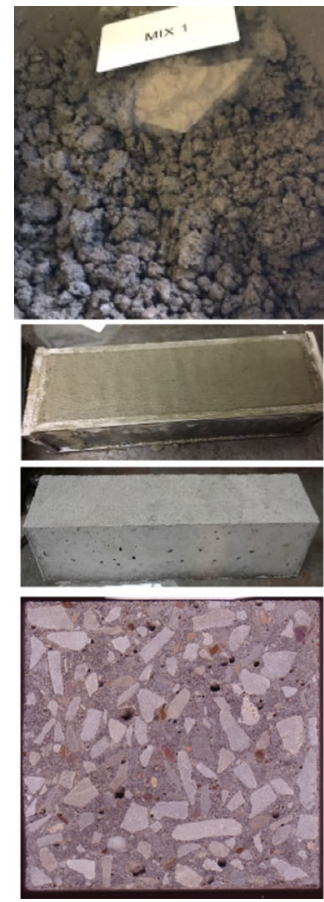

A (w/c 0.35)
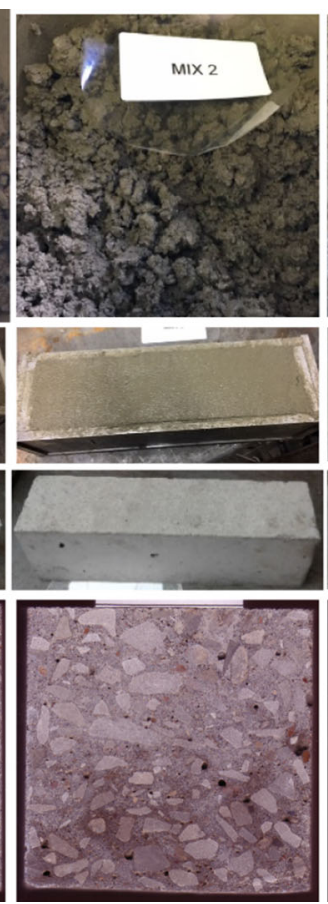

$\mathrm{C}(\mathrm{w} / \mathrm{c} 0.40)$
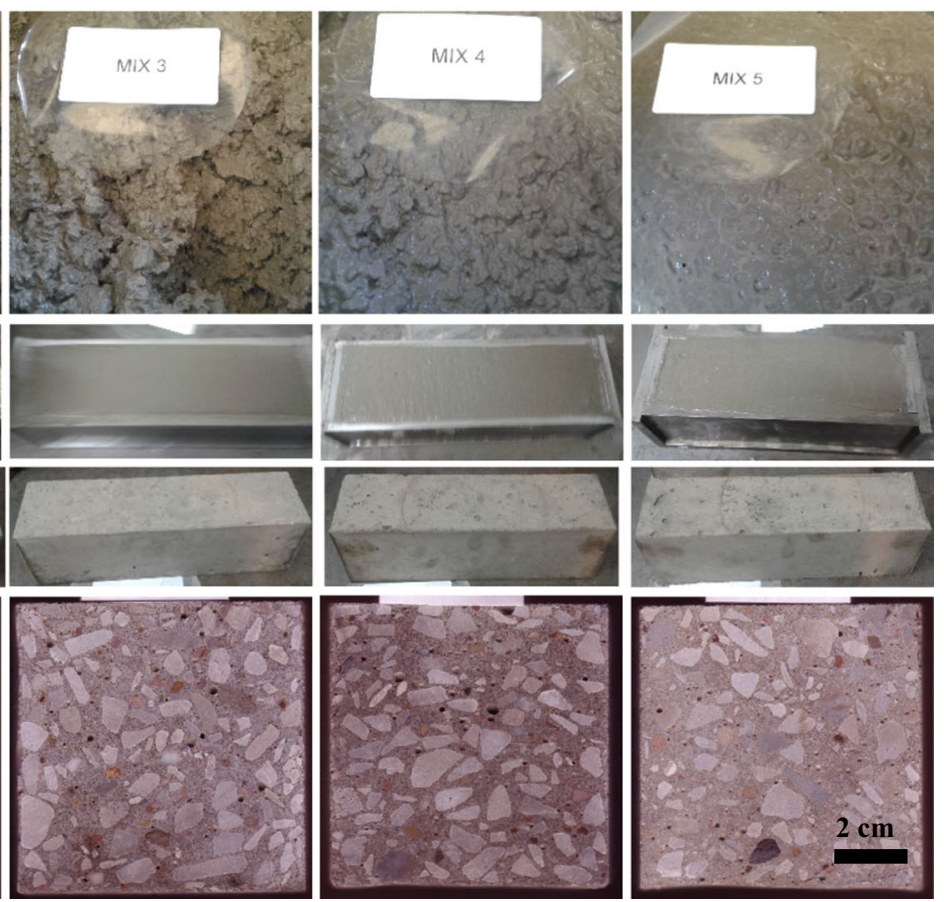

$\mathrm{E}(\mathrm{w} / \mathrm{c} 0.45)$

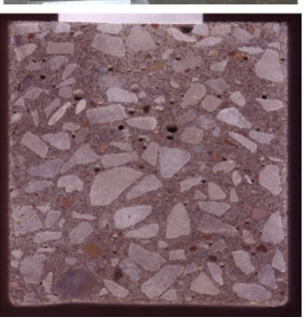

$\mathrm{B}(\mathrm{w} / \mathrm{c} 0.50)$
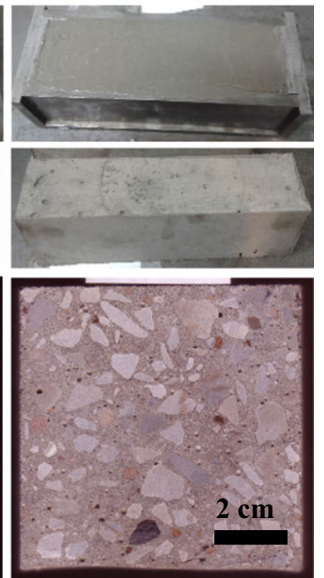

$\mathrm{D}(\mathrm{w} / \mathrm{c} 0.55)$

Fig. 1 Photographs showing (from top to bottom row) freshly mixed and compacted concrete, cast prisms $(75 \times 75 \times 300 \mathrm{~mm})$ and cross-section scans $(75 \times 75 \mathrm{~mm})$ showing homogeneous distribution of coarse aggregate particles

microscopy. It is also worth noting that several participants (Labs 02, 07) combined VA and FM-V.

By June 2018, 11 participating laboratories had submitted detailed reports and their sets of 5 results. Some had presented more than one set, either by using more than one method (Lab 14), or by having several petrographers applying the same method to estimate w/c ratio (Labs 02, 04 and 09). These are denoted as result set (a), (b) et cetera (see Table 2). In total, 20 complete sets of results, or 100 individual $\mathrm{w} / \mathrm{c}$ ratio determinations were obtained.

\section{Results}

\subsection{Estimated w/c ratios}

The obtained results are summarised in Table 4 . Note that Labs 01, 08, 09 and 14 reported some of their results as ranges. There are various statistical options for dealing with such values, but it was decided based on both the nature of the tests and the main objective of the study, to treat each range as the mid-point, and to treat inequalities as the actual value. Therefore, if a lab returned a w/c estimate as ranging from $x$ to $y$, then the average $[=(x+y) / 2]$ was plotted. If a lab estimated w/c as $<x$ (or as $>x$ ), then $x$ was taken as the returned value.

It is also worth noting that accuracy measures were claimed for many of the results, i.e. in the form of w/c \pm error. Examining the detailed submissions indicated that some measures were based on statistical analysis. For example, the estimated errors provided by Lab 05 were based on the standard deviation of two replicates per series (30 images each) while those of Lab 11 were based on the $95 \%$ confidence interval (two replicates, 30 images each). However, the claimed errors reported by other labs were nonquantifiable and based on 'previous work experience'. It was therefore decided not to use this information. Additionally, it has little bearing on the main objective of the study.

From the 20 sets of w/c ratio estimates, 14 sets (70\%) from 7 laboratories (64\% of participating labs) gave the exact correct order of mix w/c ratios from low 
Table 2 Summary of specimen and methodology used by each participating laboratory

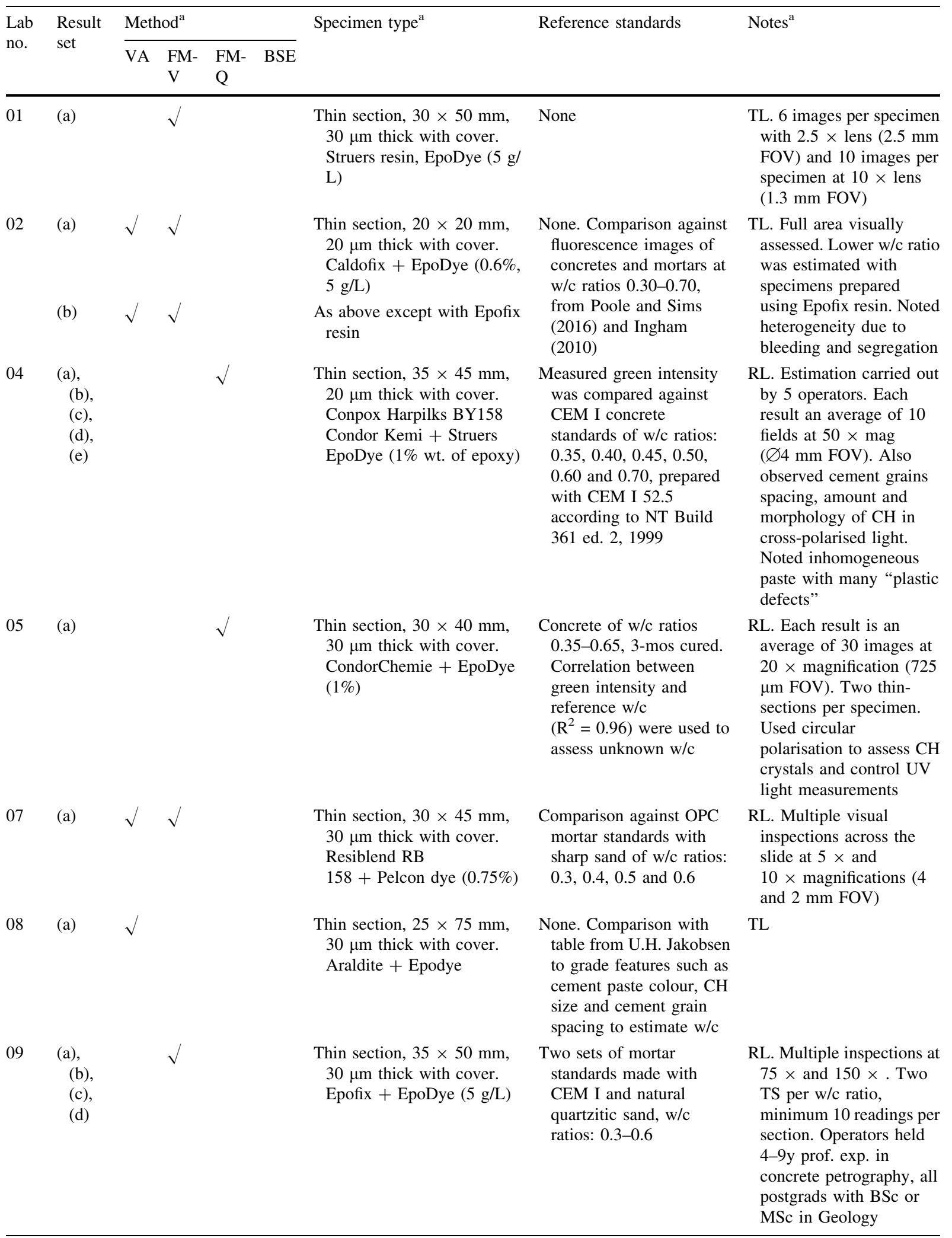


Table 2 continued

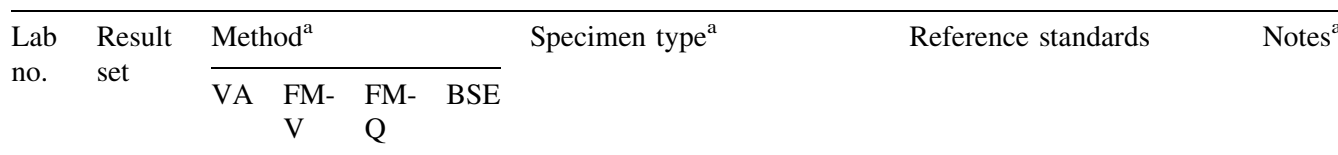

11 (a)

a)

12

(a)

$\sqrt{ }$

(a)

(a)

(b)
Polished block,

$17 \times 40 \times 8 \mathrm{~mm}$. Epofix + EpoDye $(5 \mathrm{~g} / \mathrm{L})$
The method does not require reference standards
Thin section, $45 \times 67 \mathrm{~mm}$, $30 \mu \mathrm{m}$ thick without coverslip.

Araldite + EpoDye $(0.2 \%$

wt.)

Thin section, $45 \times 60 \mathrm{~mm}$, $30 \mu \mathrm{m}$ thick with cover.

Epotek + EpoDye (0.5\%)

Thin section, $50 \times 75 \mathrm{~mm}$, $30 \mu \mathrm{m}$ thick with cover. MSDS + EpoDye (5 g/L)
Comparison made against CEM I concretes at w/c ratios: $0.35,0.400 .45$, $0.50,0.55,0.60,0.65$ and 0.70

No reference standards. Determination was based on extrapolation from Fig. 4.62 of Poole and Sims (2016)

Two sets of concrete standards with w/c ratios: $0.30,0.35,0.40,0.45$, $0.50,0.55$ and 0.60 , with crushed rock or gravel, and natural sand

\author{
30 BSE images per \\ specimen at \\ $500 \times(228 \times 171 \mu \mathrm{m}$ \\ $\mathrm{FOV}$ at $0.1 \mu \mathrm{m}$ pixel \\ size). Two replicates per \\ w/c ratio. Noted \\ heterogeneous paste \\ microstructure. \\ Estimated values are \\ "free" w/c ratio, \\ assuming no water lost to \\ bleeding and evaporation \\ in fresh concrete
}

$\mathrm{RL}+\mathrm{TL}$, Entire TS scanned and 5-10 representative areas examined at $200 \times(2 \mathrm{~mm}$ FOV $)$. Porosity distribution suggests mix water not uniformly distributed

RL. One observation per specimen at $10 \times$ magnification (2.6 mm FOV)

RL. 7 per TS, averaged over 952 fluorescence measurements. Objective lens $20 \times, 10 \times$ and $5 \times(1,2$ and $4 \mathrm{~mm}$ FOV). Noted large standard deviation and standard error. These suggest results are not reliable, and that there are variables, in addition to $\mathrm{w} / \mathrm{c}$, that may have affected results e.g. differences in preparation, and differences between unknown specimen and reference standards

RL. Visual comparison of microporosity, portlandite and unreacted cement
Thin section, $50 \times 75 \mathrm{~mm}$,
$30 \mu \mathrm{m}$ thick with cover Robnor + Orasol Blue $(0.7 \mathrm{~g} / 100 \mathrm{~g})$

\footnotetext{
${ }^{a} V A$ visual assessment of cement paste characteristics, $F M$ - $V$ visual assessment of fluorescent intensity $F M$ - $Q$ quantitative assessment of fluorescent intensity, $B S E$ quantitative backscattered electron microscopy, $T S$ thin-section, $P B$ polished block, $R L$ reflected light, $T L$ transmitted light, FOV field of view
} 
Table 3 Description of microscopy methods used for determining w/c ratio

\begin{tabular}{|c|c|c|c|}
\hline Method $^{\mathrm{a}}$ & Labs & Description & Limitations \\
\hline VA & $\begin{array}{l}02 \\
07 \\
08 \\
14\end{array}$ & $\begin{array}{l}\text { The basis of this method is that variations in free w/c } \\
\text { ratio lead to variations in microstructural features of } \\
\text { the cement paste that can be observed on thin sections: } \\
\text { - Physical appearance: High w/c produces weak friable } \\
\text { cement paste, segregation and excessive bleeding. } \\
\text { Low w/c results in dense dark-coloured paste due to } \\
\text { abundance of unhydrated cement. } \\
\text { - Cement hydration: High w/c generally results in } \\
\text { higher degree of hydration and reduced amounts of } \\
\text { unreacted cement. The residual cement grains are } \\
\text { spaced farther apart. } \\
\text { - Portlandite: High w/c tends to increase the amount, } \\
\text { size and clustering of portlandite. } \\
\text { - Capillary porosity: High w/c increases the capillary } \\
\text { porosity of the cement paste. } \\
\text { It is important to note that these features are indicators } \\
\text { of w/c and none should be viewed in isolation. The } \\
\text { use of suitable reference concretes of known w/c } \\
\text { ratios to compare against the test concrete can greatly } \\
\text { assist this method. }\end{array}$ & $\begin{array}{l}\text { Many factors could lead to uncertainties. For example, } \\
\text { presence of water reducing admixture (plasticiser) can } \\
\text { reduce the degree of hydration and capillary porosity, } \\
\text { especially at high dosages. Similarly, supplementary } \\
\text { cementitious materials (SCMs) can influence the } \\
\text { degree of hydration, capillary porosity and portlandite } \\
\text { content. Curing temperature, humidity and duration } \\
\text { affects the degree of hydration, which in turn affects } \\
\text { the amounts of portlandite, unreacted cement and } \\
\text { capillary porosity, irrespective of w/c ratio. The above } \\
\text { is by no means exhaustive. Therefore, this method is } \\
\text { highly dependent on the experience of the } \\
\text { petrographer and ability to recognise conflicts, for } \\
\text { example between the degree hydration and capillary } \\
\text { porosity, that could lead to uncertainty in the } \\
\text { estimated w/c. }\end{array}$ \\
\hline FM-V & $\begin{array}{l}01 \\
02 \\
07 \\
09 \\
12 \\
13\end{array}$ & $\begin{array}{l}\text { The w/c of an unknown concrete is determined by } \\
\text { comparing the capillary porosity of its cement paste, } \\
\text { as indicated by fluorescence intensity, to a set of } \\
\text { reference concretes of similar type made with known } \\
\text { w/c ratios. The greater the w/c, the greater the } \\
\text { capillary porosity, the intruded resin and the observed } \\
\text { fluorescence. Visual comparison of fluorescence } \\
\text { intensity is one of the most commonly used } \\
\text { techniques. }\end{array}$ & $\begin{array}{l}\text { The method is highly sensitive to small variations in the } \\
\text { thin section such as thickness, epoxy penetration, dye } \\
\text { concentration and dispersion. Thin sections of the } \\
\text { reference and test sample must be exactly the same } \\
\text { thickness and made with the same procedure. } \\
\text { Presence of glassy translucent SCMs (e.g. slag) will } \\
\text { influence fluorescence intensity. Reference standards } \\
\text { should be made of the same materials and cured to the } \\
\text { same degree of hydration as that of the test samples, }\end{array}$ \\
\hline FM-Q & $\begin{array}{l}04 \\
05 \\
14\end{array}$ & $\begin{array}{l}\text { See FM-V above. The comparison of fluorescence } \\
\text { intensity is made via automated or semi-automated } \\
\text { image analysis. Fluorescence intensity is measured } \\
\text { directly using a photodiode attached to the microscope } \\
\text { or estimated by averaging the grey value (brightness) } \\
\text { of pixels associated to the cement paste. This is } \\
\text { potentially more precise than visual assessment as } \\
\text { very small differences in fluorescence intensity can be } \\
\text { detected that may not be visible to the human eye. }\end{array}$ & $\begin{array}{l}\text { but this is difficult to achieve if the concrete is } \\
\text { unknown. The method is also sensitive to factors other } \\
\text { than w/c ratio that influence capillary porosity (see } \\
\text { VA above) and some experience is required in } \\
\text { assessing whether or not this technique is appropriate } \\
\text { for a given type of concrete. }\end{array}$ \\
\hline BSE & 11 & $\begin{array}{l}\text { This method calculates the original cement content, } \\
\text { water content and free w/c ratio of the unknown } \\
\text { concrete from its microstructural phase assemblage. } \\
\text { This is done by measuring the volume fractions of } \\
\text { capillary pores, hydration products and residual } \\
\text { unreacted cement of the hardened concrete with image } \\
\text { analysis on SEM-BSE micrographs. The method also } \\
\text { measures the degree of hydration of the unknown } \\
\text { concrete. It is quantitative and does not require } \\
\text { comparison with reference standards made of the } \\
\text { same materials and cured to the same hydration } \\
\text { degree as the unknown concrete. }\end{array}$ & $\begin{array}{l}\text { Requires relatively more advanced instrumentation and } \\
\text { experience in image analysis. Because it calculates } \\
\text { free w/c ratio, the method tends to underestimate } \\
\text { mixes at high w/c ratios if the water lost to aggregate } \\
\text { absorption, bleeding and evaporation from fresh } \\
\text { concrete is not considered. These factors would also } \\
\text { affect the other techniques above. Similarly, the } \\
\text { methods are only applicable to concretes that have not } \\
\text { experienced physical or chemical degradation such } \\
\text { that significant microstructural changes have } \\
\text { occurred. }\end{array}$ \\
\hline
\end{tabular}

${ }^{a} V A$ visual assessment of cement paste characteristics, $F M-V$ visual assessment of fluorescent intensity, $F M-Q$ quantitative assessment of fluorescent intensity, BSE quantitative backscattered electron microscopy 
Table 4 Estimated w/c ratios from all participants

\begin{tabular}{|c|c|c|c|c|c|c|c|}
\hline \multirow{2}{*}{$\begin{array}{l}\text { Lab } \\
\text { ref. }\end{array}$} & \multirow[t]{2}{*}{ Method } & \multicolumn{5}{|c|}{ Mix ID (target w/c ratio) } & \multirow{2}{*}{$\begin{array}{l}\text { Mean abs. } \\
\text { error } \pm \mathrm{SD}\end{array}$} \\
\hline & & $\mathrm{A}(0.35)$ & $\mathrm{C}(0.40)$ & $\mathrm{E}(0.45)$ & $\mathrm{B}(0.50)$ & $\mathrm{D}(0.55)$ & \\
\hline 01 & FM-V & 0.5 & $>0.45$ & 0.60 & $<0.65$ & 0.55 & $0.10 \pm 0.07$ \\
\hline 02 (a) & $\begin{array}{l}\text { VA, FM- } \\
\text { V }\end{array}$ & $0.40 \pm 0.1$ & $0.50 \pm 0.1$ & $0.45 \pm 0.1$ & $0.55 \pm 0.1$ & $0.65 \pm 0.1$ & $0.06 \pm 0.04$ \\
\hline 02 (b) & $\begin{array}{l}\text { VA, FM- } \\
\text { V }\end{array}$ & $0.35 \pm 0.1$ & $0.40 \pm 0.1$ & $0.50 \pm 0.1$ & $0.55 \pm 0.1$ & $0.65 \pm 0.1$ & $0.04 \pm 0.04$ \\
\hline 04 (a) & FM-Q & 0.35 & 0.40 & 0.50 & 0.60 & 0.70 & $0.06 \pm 0.07$ \\
\hline 04 (b) & FM-Q & 0.43 & 0.47 & 0.56 & 0.70 & 0.78 & $0.14 \pm 0.07$ \\
\hline $04(\mathrm{c})$ & FM-Q & 0.35 & 0.40 & 0.50 & 0.55 & 0.60 & $0.03 \pm 0.03$ \\
\hline $04(\mathrm{~d})$ & FM-Q & 0.37 & 0.40 & 0.53 & 0.65 & 0.75 & $0.09 \pm 0.09$ \\
\hline 04 (e) & FM-Q & 0.35 & 0.40 & 0.50 & 0.60 & 0.70 & $0.06 \pm 0.07$ \\
\hline 05 & FM-Q & $0.35 \pm 0.04$ & $0.38 \pm 0.03$ & $0.47 \pm 0.06$ & $0.51 \pm 0.03$ & $0.61 \pm 0.03$ & $0.02 \pm 0.02$ \\
\hline 07 & $\begin{array}{l}\text { VA, FM- } \\
\text { V }\end{array}$ & $0.30 \pm 0.05$ & $0.40 \pm 0.05$ & $0.45 \pm 0.05$ & $0.50 \pm 0.05$ & $0.55 \pm 0.05$ & $0.01 \pm 0.02$ \\
\hline 08 & VA & $<0.35$ & $<0.35$ & $0.45-0.55$ & $>0.55$ & $0.45-0.55$ & $0.04 \pm 0.02$ \\
\hline 09 (a) & FM-V & $<0.3 \pm 0.1$ & $0.35-0.4 \pm 0.05$ & $0.4-0.50 \pm 0.05$ & $0.50 \pm 0.1$ & $0.60 \pm 0.1$ & $0.03 \pm 0.03$ \\
\hline 09 (b) & FM-V & $0.4 \pm 0.05$ & $0.45 \pm 0.05$ & $0.5 \pm 0.05$ & $0.6 \pm 0.05$ & $0.65-0.7 \pm 0.1$ & $0.10 \pm 0.05$ \\
\hline 09 (c) & FM-V & $0.35 \pm 0.1$ & $0.4 \pm 0.1$ & $0.45 \pm 0.1$ & $0.5 \pm 0.1$ & $0.6 \pm 0.1$ & $0.01 \pm 0.02$ \\
\hline 09 (d) & FM-V & $0.4 \pm 0.1$ & $0.45 \pm 0.1$ & $0.5 \pm 0.1$ & $0.6 \pm 0.1$ & $0.7 \pm 0.1$ & $0.08 \pm 0.05$ \\
\hline 11 & BSE & $0.35 \pm 0.02$ & $0.41 \pm 0.02$ & $0.44 \pm 0.02$ & $0.46 \pm 0.02$ & $0.50 \pm 0.02$ & $0.02 \pm 0.02$ \\
\hline 12 & FM-V & $0.46 \pm 0.1$ & $0.42 \pm 0.1$ & $0.50 \pm 0.1$ & $0.55 \pm 0.1$ & $0.60 \pm 0.1$ & $0.06 \pm 0.03$ \\
\hline 13 & $\begin{array}{l}\text { VA, FM- } \\
\text { V }\end{array}$ & 0.50 & 0.55 & 0.60 & 0.65 & 0.70 & $0.15 \pm 0.00$ \\
\hline 14 (a) & FM-Q & $0.35 \pm 0.1$ & $0.35-0.4 \pm 0.1$ & $0.45-0.5 \pm 0.1$ & $0.55-0.6 \pm 0.1$ & $0.55 \pm 0.1$ & $0.03 \pm 0.03$ \\
\hline 14 (b) & VA & $0.35 \pm 0.05$ & $0.40 \pm 0.05$ & $0.50 \pm 0.05$ & $0.60 \pm 0.05$ & $0.55 \pm 0.05$ & $0.03 \pm 0.05$ \\
\hline
\end{tabular}

to high (A, C, E, B, D) regardless of the error. These were Labs 02b, 04a-e, 05, 07, 09a-d, 11 and 13.

In the detailed submissions, many labs provided micrographs showing typical microstructural features of their sub-specimens. An example is shown in Fig. 2. The submitted micrographs clearly show that the specimens have distinct fluorescence intensity and capillary porosity. Specimen A had the lowest florescence intensity and capillary porosity, followed by $\mathrm{C}$, $\mathrm{E}, \mathrm{B}$ and $\mathrm{D}$, in line with the increase in w/c ratio. Specimens with higher w/c ratio also had lower amount of unreacted cement, but larger amount and size of portlandite, again consistent with expectation.

\subsection{Comparison between laboratories and methods}

Figure 3 shows the estimated w/c ratios plotted against actual mix values from all participants. Results from laboratories that did not use reference standards (Labs 01, 02, 08, 13) are plotted separately to those from laboratories that did, the latter divided into FM-V (Labs 07, 09, 12, 14b) and FM-Q (Labs 04, 05, 14a). Data from the BSE method are treated as a separate category. Figure 4 presents the errors in the estimated w/c ratios for each participant, grouped according to the method used.

The data show that errors ranged from -0.058 to +0.23 or from -14 to $+43 \%$ of the actual w/c ratios. The magnitude of error appears to be independent of the w/c ratio in some labs, but increased with increasing w/c for Labs 04, 05, 09 and 11. Of the 100 

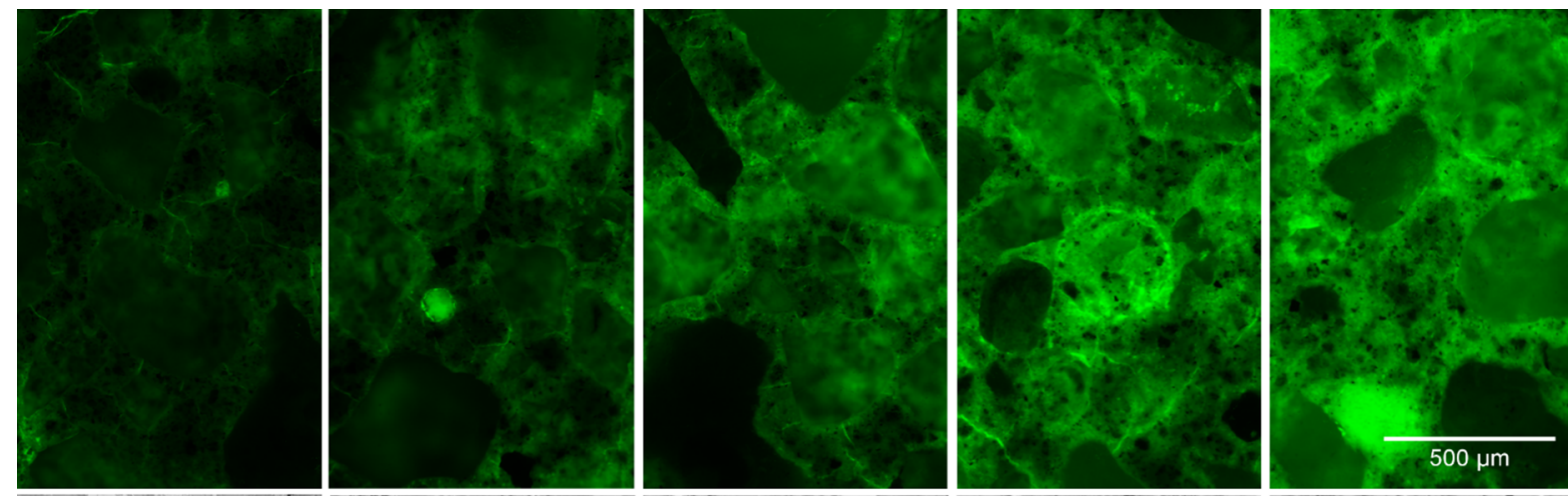

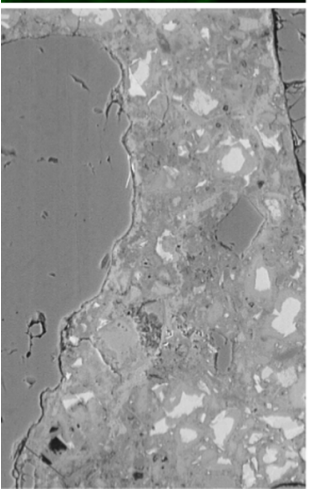

$\mathrm{A}(\mathrm{w} / \mathrm{c} 0.35)$

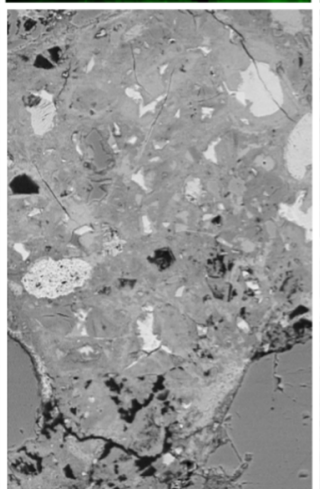

$\mathrm{C}(\mathrm{w} / \mathrm{c} 0.40)$

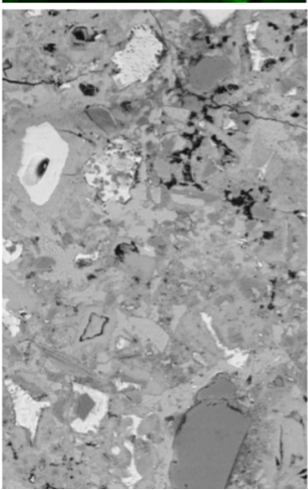

$\mathrm{E}(\mathrm{w} / \mathrm{c} 0.45)$

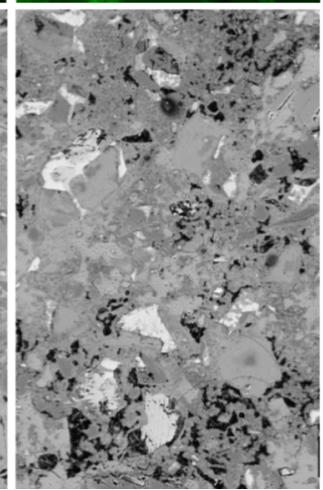

$\mathrm{B}(\mathrm{w} / \mathrm{c} 0.50)$

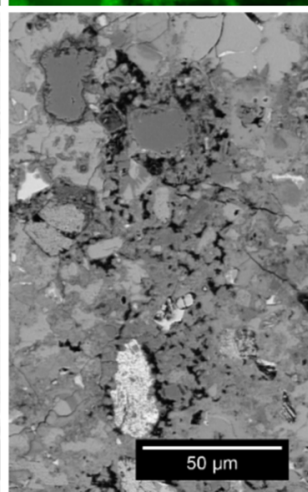

$\mathrm{D}(\mathrm{w} / \mathrm{c} 0.55)$

Fig. 2 Fluorescence imaging (top row) shows increasing fluorescence intensity with increasing w/c ratio. BSE imaging (bottom row) shows increasing capillary porosity and decreasing unreacted cement content with increasing w/c ratio. Source: Lab 11

individual determinations, $61 \%$ over-estimated $\mathrm{w} / \mathrm{c}$ ratio (positive errors), $29 \%$ were exact, and only $10 \%$ were under-estimated (negative errors). This suggests that there is a tendency for w/c ratio to be overestimated, particularly for VA, FM-V and FM-Q methods. Implications of this will be discussed later.

The mean error for each lab ranged from as low as $0.01-0.15$ (Table 4). It should be noted that the mean error is calculated using absolute values so that positive and negative errors do not cancel. There is a clear variation in performance between labs, even when using the same method, or between operators from the same lab applying a particular method to the same sub-specimen set and reference standards (Lab 04 and 09). This suggests that some amount of subjectivity is inevitable when interpreting fluorescence intensity. The largest errors occurred in Lab 01 and 13. Lab 01 over-estimated w/c by 0.15 in the majority of their results. Lab 13 consistently overestimated w/c by 0.15 , but gave the correct order. Both labs did not use reference standards.
It is also worth noting that several labs performed consistently well across the range with low errors for all specimens. Those that returned the most accurate estimates were Labs 07 (VA + FM-V), 14b (VA), 05 (FM-Q), 14a (FM-Q) and 11 (BSE), with errors no greater than 0.05 .

Figure 5 shows the maximum, minimum and average absolute error in the estimated w/c ratio, grouped to test method. Data from the UK Concrete Society inter-laboratory precision trial [3] using the BS 1881-124 physicochemical method are also included for comparison (discussed later). Overall, the microscopy-based methods gave much lower errors than the BS 1881-124 method. Within the optical microscopy methods (VA, FM-V, FM-Q), labs that used reference standards performed better than those that did not. The BSE method gave the lowest range and average error, the magnitude of these are similar to those reported in an earlier study [22].

Figure 6 presents the frequency distribution and cumulative histogram of absolute error from all w/c 


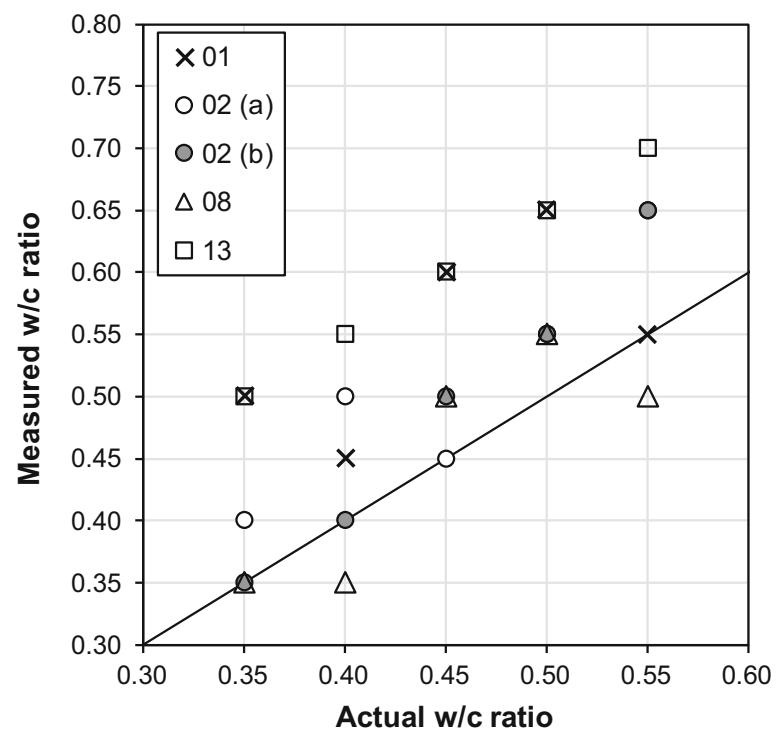

(a) VA \& FM-V (No reference standards)

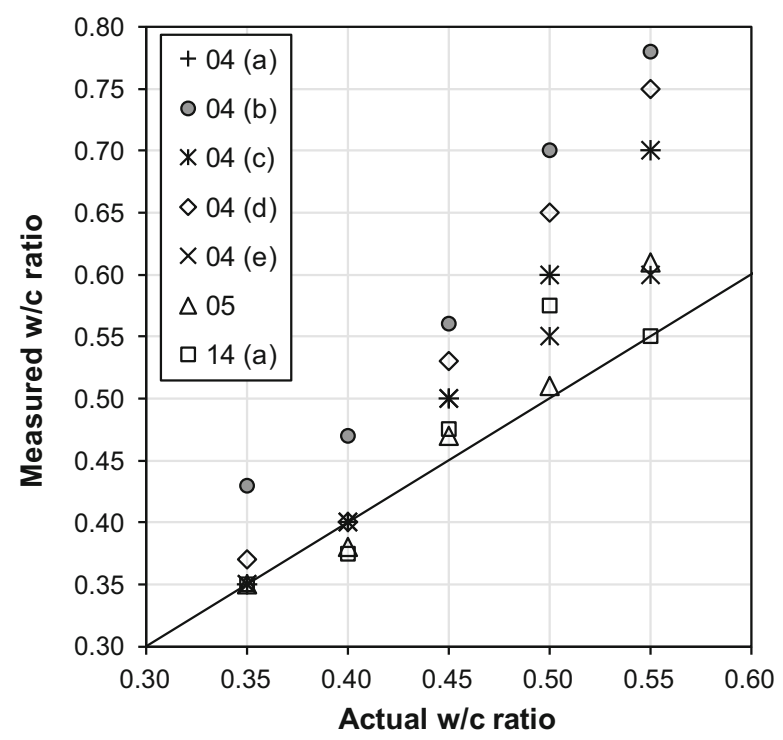

(c) FM-Q (With reference standards)

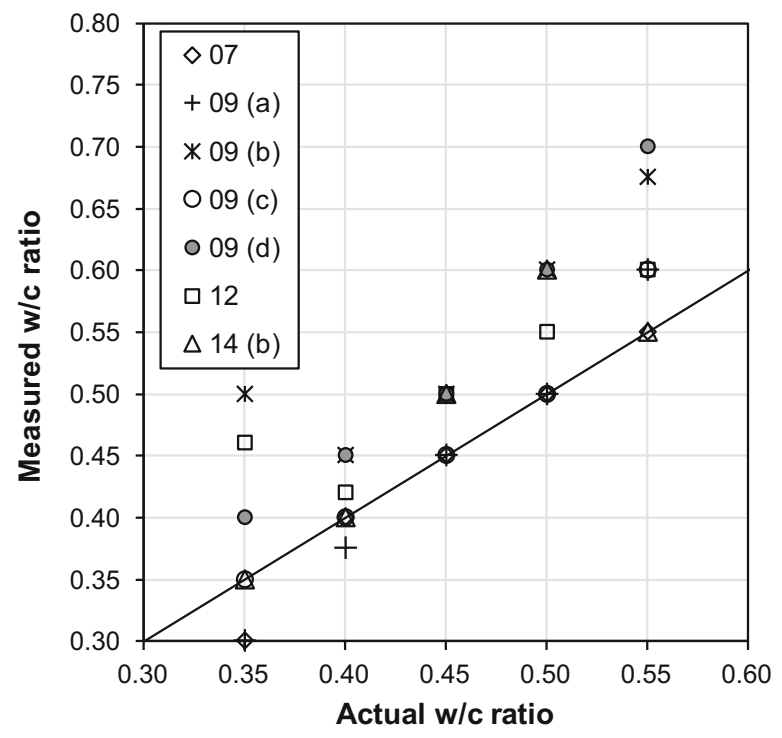

(b) VA \& FM-V (With reference standards)

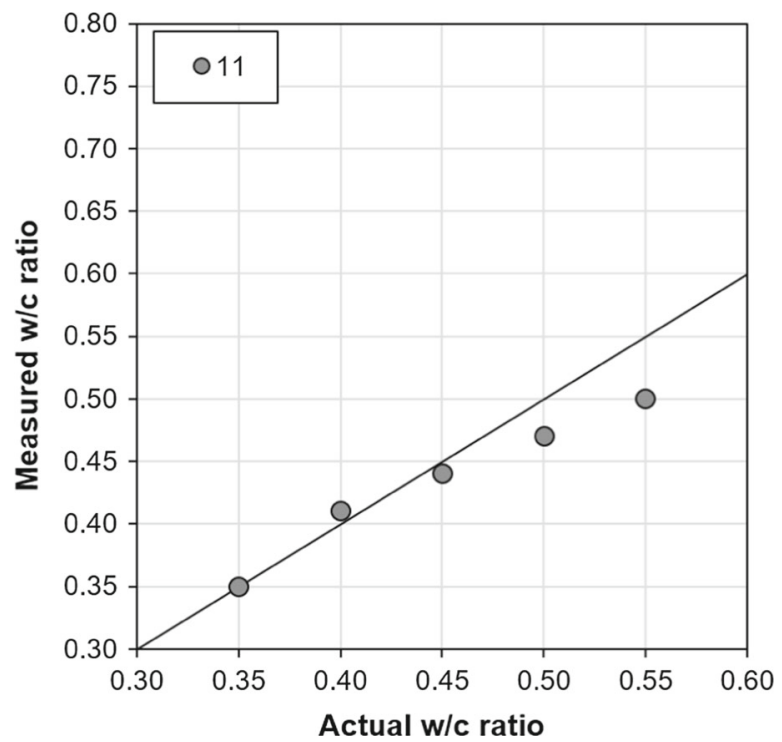

(d) BSE (Standards not required)

Fig. 3 Comparison between estimated and actual w/c ratios for all participating laboratories

ratio determinations (100) in this study. The data show that $37 \%$ of the estimated w/c ratios are within 0.025 of the target mix values, $58 \%$ are within 0.05 and $81 \%$ are within 0.1 . In contrast, only $68 \%$ of the estimated w/c ratios using BS 1881-124 are within 0.1 of the target mix values.

\subsection{Comparison to BS 1881-124}

The Concrete Society inter-laboratory precision trial [3] was conducted in 2012-13 to investigate the accuracy of BS 1881-124 [1] for determining the contents of cement, chloride, sulfate and w/c ratio. Four contemporary concrete mixes were prepared: 


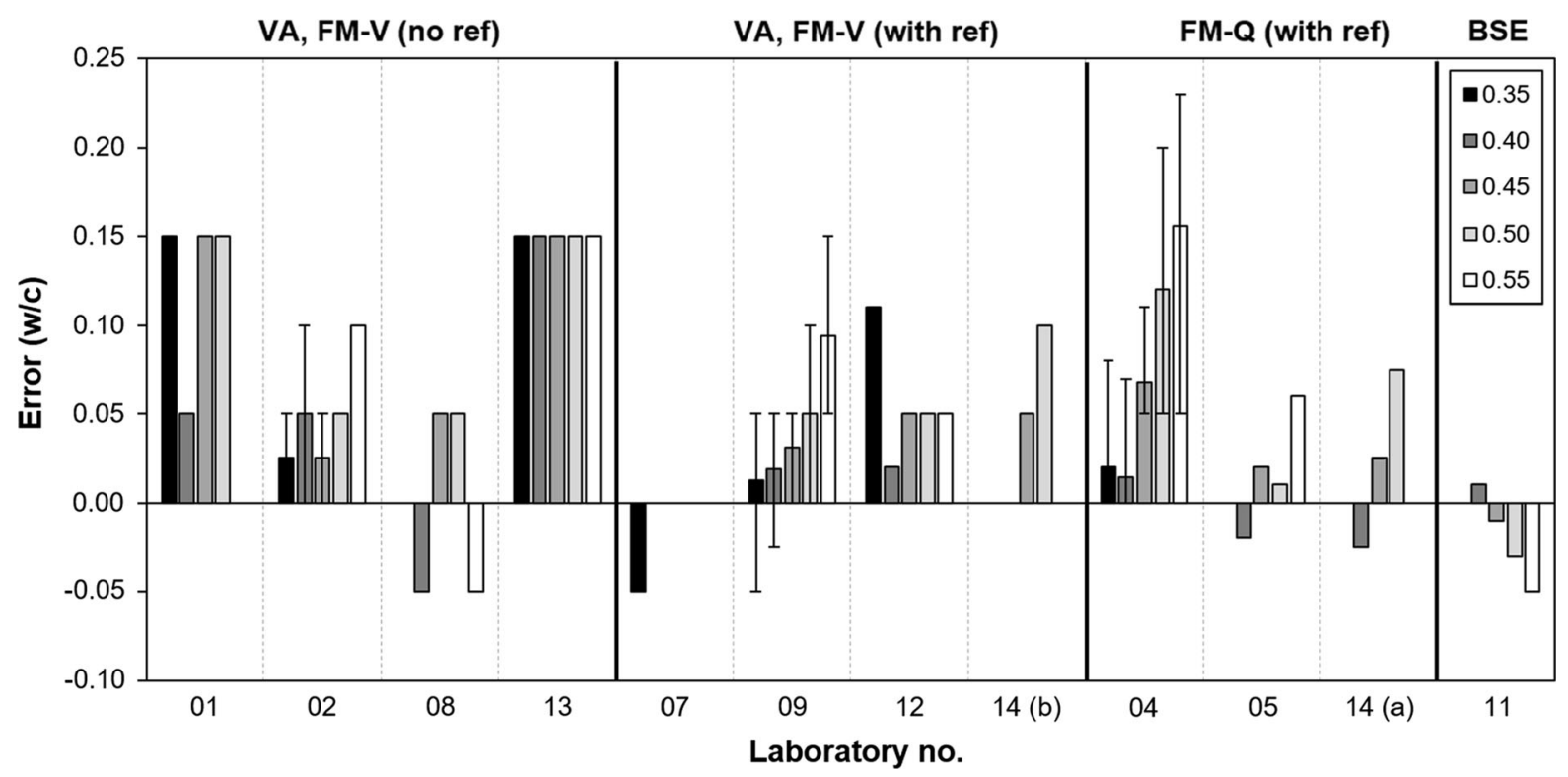

Fig. 4 Error in the estimated w/c ratio for each laboratory, grouped according to method used. Error bars represent the range of error observed

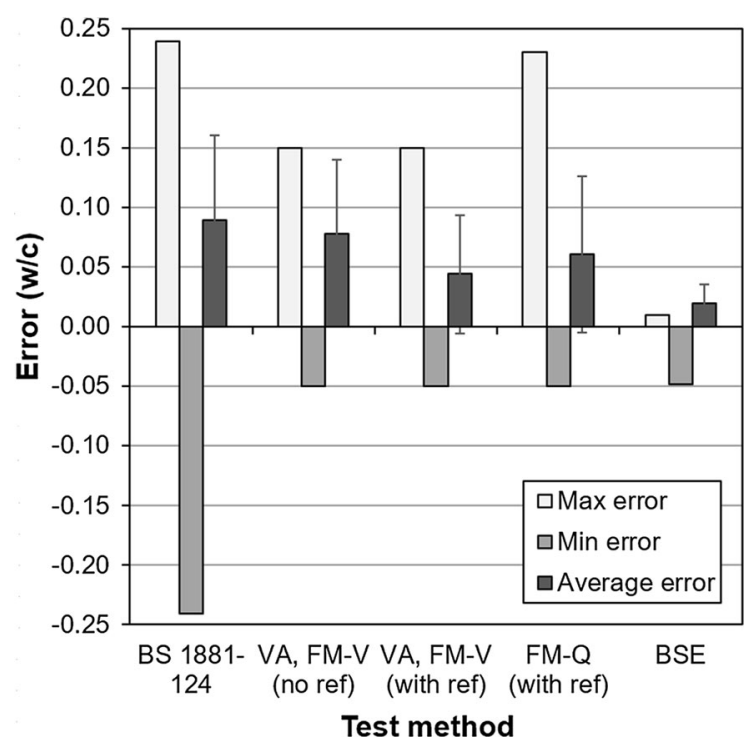

Fig. 5 Maximum error, minimum error and average absolute error in the estimated $\mathrm{w} / \mathrm{c}$ ratio, grouped according to test method. Data for the BS 1881-124 method is from Mix 3 and 4 of Concrete Society TR32 [3]. Error bars represent \pm standard deviation

Mix 1 and 2 were blended with fly ash and slag respectively, while Mix 3 and 4 had CEM I only with target free w/c ratios of 0.44 and $0.59 .100 \mathrm{~mm}$ cube specimens (56-day cured) were then distributed to 11
UKAS accredited construction materials testing labs for a round-robin assessment, of which 7 labs estimated w/c ratio. Full details are published elsewhere $[3,5,6]$. In this comparison we will ignore the blended mixes and use only data from Mix 3 and 4. In total, 29 separate w/c determinations were obtained. The estimated $\mathrm{w} / \mathrm{c}$ ratios had errors ranging from -0.24 to +0.24 or from -38 to $+45 \%$ of the mix values. The average error for each lab ranged from 0.03 to 0.18 . Average error for all 29 determinations was 0.08 . When these are compared to our data (Table 4, Figs. 4, 5, 6), it is clear that microscopy methods are more accurate and reliable compared to BS 1881-124.

The application of microscopy techniques for determining $w / c$ ratio is based on the principle that capillary porosity of cement paste increases as w/c ratio increases. Using microscopy, it is possible to directly establish the microporosity of the cement paste rather than the concrete as a whole. This is a significant advantage over other porosity based test methods such as that given in BS 1881-124 [1], which cannot distinguish capillary porosity from porosity due to aggregate particles, air voids and cracks. Furthermore, the BS 1881-124 method requires a separate determination of cement content by chemical analysis of soluble silica and calcium oxide content 


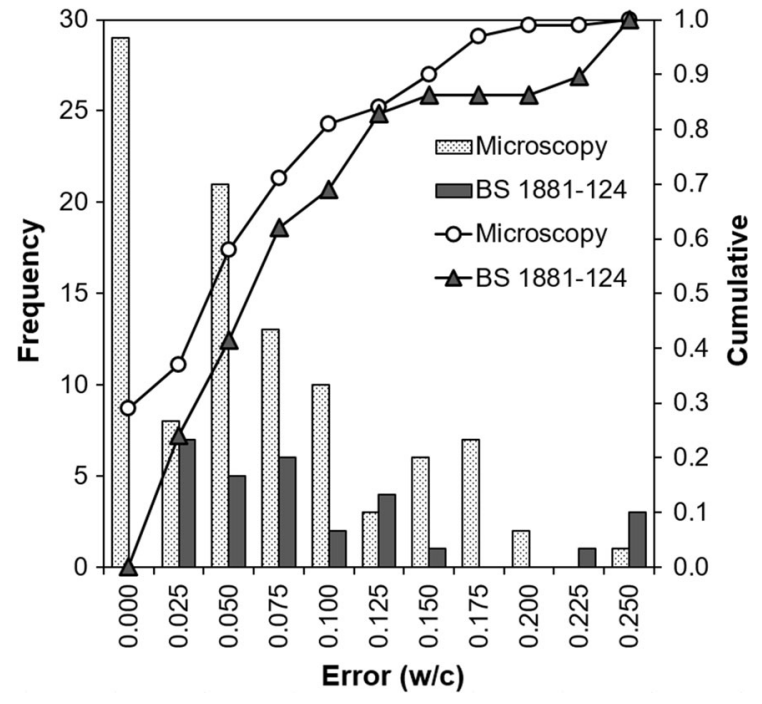

Fig. 6 Frequency and cumulative histograms of absolute error (w/c) show improved accuracy of the microscopy methods tested in this study $(n=100)$ compared to the BS 1881-124 method (data from Mix 3 and 4 of Ref [3], $n=29$ )

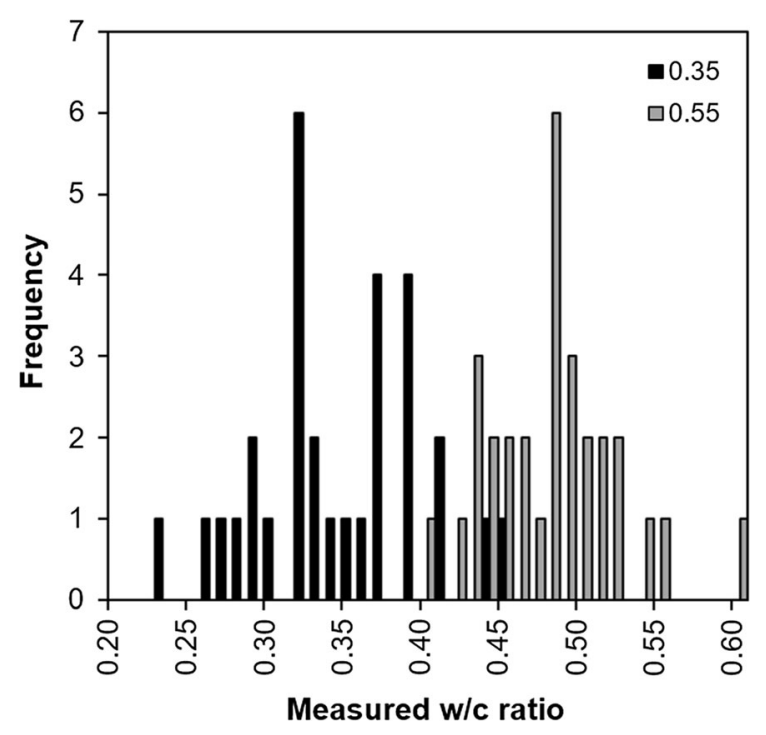

Fig. 7 Distribution of the estimated w/c ratios from Lab 11 for Mix A and D showing heterogeneity of the microstructure. Data from 30 images per specimen, each captured at field of view of $228 \times 171 \mu \mathrm{m}$

and this is also prone to various errors [3]. In contrast, microscopy methods do not require a priori knowledge of the aggregates and cement content, or presence of voids and cracks [2].

\subsection{Other observations}

A recurring observation from several labs was the nonuniform distribution of microporosity in their subspecimens. For example, Lab 02 observed that "all five samples has a heterogeneous texture" and reported signs of "segregation and bleeding". Lab 04 noted that the paste was "inhomogeneous and with many plastic defects". According to Lab 12, the "porosity distribution suggests that mix water was not uniformly distributed". These suggest inadequate mixing or possibly artefacts from compaction and this may be factor in some of the outlying results. However, it is not unusual for concrete to show heterogeneous pore structure when viewed microscopically, even for laboratory prepared specimens, due to the random distribution and relative movement of water and cement that vary on a local scale. Presence of aggregate particles further increases heterogeneity by causing well-known microstructural gradients [28, 29].

To illustrate the above, Fig. 7 presents data from Lab 11 showing the spread in w/c ratio estimated from BSE images of Mix A and D. Substantial variability in the 'local' w/c ratio can be seen, ranging from 0.23 to 0.45 for Mix A and $0.40-0.60$ for Mix D, but this is consistent with data reported previously using the BSE technique [21-23]. The variability in local w/c ratio should not be surprising given that the microstructure of concrete is inherently heterogeneous and that each w/c estimate is based on the analysis of a single image of $228 \times 171 \mu \mathrm{m}$ field of view captured at high spatial resolution. Nevertheless, when a sufficiently large number of images have been measured, the cumulative average will stabilise indicating that a representative volume has been analysed.

The participating labs are expected to ensure representative sampling. However, there are differences in the magnification, resolution and number of images analysed between labs, according to their routine in house methodology (Table 2). The total area analysed per sub-specimen ranged from as low as $1 \mathrm{~mm}^{2}$ (Lab 11)-400 mm $\mathrm{mm}^{2}$ (Lab 02). This could potentially be a source of error, but Fig. 8 shows no clear correlation between lab performance and total area analysed. This is perhaps not surprising given that the size of capillary pores is in the micron range and the representative elementary volume for cement paste is $\sim 100^{3} \mu \mathrm{m}^{3}$ [30] Therefore, a sampling area of 


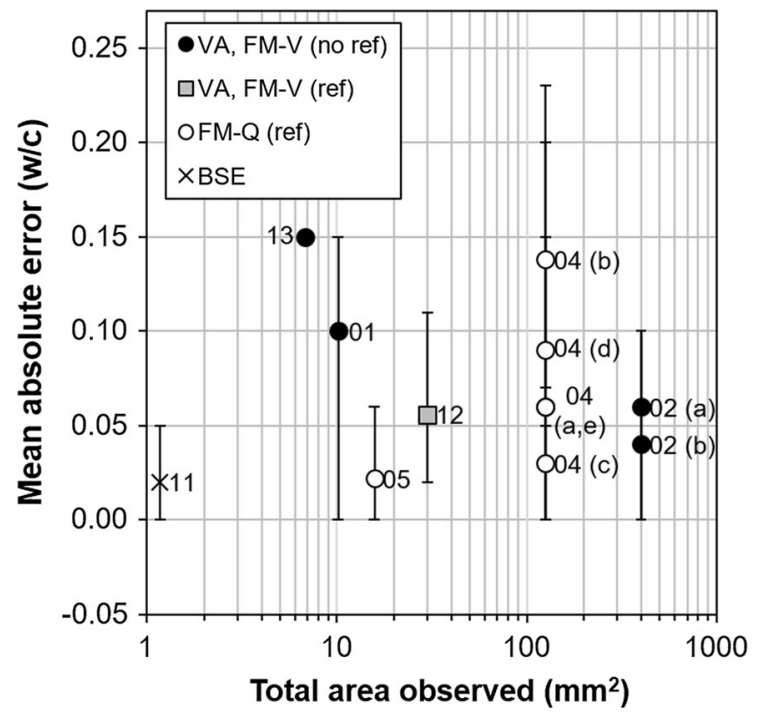

Fig. 8 Average error plotted against total area observed in each laboratory shows no clear dependency. Error bars represent the range observed

$1 \mathrm{~mm}^{2}$ is not unduly small and the variation in area analysed is not a major source of error in the estimated $\mathrm{w} / \mathrm{c}$ ratio.

\subsection{Statistical analysis}

Starting with summary statistics, distribution-free (non-parametric) statistical tests were carried out. The most basic is a rank test to establish if the labs correctly ordered the samples. This showed that only 7 out of 80 pairs were out of order, which implies that microscopy provides a good relative test for w/c ratio determination, whether or not it is a good absolute test. Furthermore, arithmetic averages (over all labs) were in strict order and showed remarkable consistency: all five averages of measured w/c ratios were over- estimates and the errors (of each mix) were well correlated with the results, cc 0.997 (confidence $>99.99 \%$ ). This implies that a simple linear calibration could provide very good absolute accuracy (discussed below), in addition to the extant relative accuracy, if given access to a sufficient number of replications.

Splitting the methods at the top level into ' $\mathrm{V}$ ' and ' $\mathrm{F}$ ', where ' $\mathrm{V}$ ' is all results using VA or FM-V and ' $\mathrm{F}$ ' is just FM-Q (and temporarily disregarding BSE because there is only one set of results), it is observed that ' $\mathrm{V}$ ' has a rank order of $5 / 16$ whereas ' $F$ ' has a rank order of $2 / 36$. This is sufficient difference to justify undertaking tests to establish whether there is statistical basis for declaring one method is better. However, the arithmetic mean error (Fig. 5) shows no clear distinction between the accuracy of the methods. There is also no significant difference between ' $\mathrm{V}$ ' and 'F' at the $80 \%$ level on a student's $T$ test for means (unknown variance).

However, there is a noticeable difference between methods when the results at each w/c ratio are analysed (Table 5). ' $\mathrm{V}$ ' shows relatively consistent positive error while ' $F$ ' shows increasing error with increase in w/c ratio. This warrants further investigation, which externally to statistical analysis could include examination of the standards used for visual comparison, the ability of the method to determine correctly at high w/c ratios, and whether the physical basis for the method scales linearly with w/c ratio. Further subdividing ' $\mathrm{V}$ ' into VA and FM-V did not introduce any further significant differences in these statistical tests.

Having noted that the errors appear to be linearly related to data values, we investigated the possibility that each could be corrected using a straight-line calibration based on a least squared error fit within its
Table 5 Percentage error at individual $\mathrm{w} / \mathrm{c}$ ratio

\begin{tabular}{llcllc}
\hline Method & \multicolumn{4}{l}{ Mix ID (target w/c ratio) } \\
\cline { 2 - 6 } & $\mathrm{A}(0.35)(\%)$ & $\mathrm{C}(0.40)(\%)$ & $\mathrm{E}(0.45)(\%)$ & $\mathrm{B}(0.50)(\%)$ & $\mathrm{D}(0.55)(\%)$ \\
\hline V (VA and FM-V) & 8.9 & 5.5 & 10.0 & 12.5 & 9.5 \\
F (FM-Q) & 1.1 & -1.3 & 11.3 & 19.0 & 20.0 \\
After correction using simple linear calibration & & & \\
V (VA and FM-V) & 2.3 & -2.1 & -1.3 & 0.9 & 0.3 \\
F (FM-Q) & 4.4 & -6.2 & 0.0 & 2.6 & -0.6 \\
\hline
\end{tabular}


own subdivided data set. Whilst this is the same underlying principle (a least squared errors) as underpins bivariate regression, which is a parametric test, we are not making any assumptions about distributions if we simply fit a straight line by minimising the errors of the points from the line. The correction reduces the errors to those shown in Table 5. This indicates that calibration and formalisation of standards may have the potential to improve the accuracy of these methods.

\section{Discussion}

\subsection{Importance of reference standards}

It is critically important for optical microscopy-based methods (VA, FM-V, FM-Q) to use suitable reference standards to which the fluorescence intensity and/or other microstructural features of the test concrete can be compared against. The references should ideally be made of the same composition (cement type, mineral additions, admixtures, aggregates), cured in the same manner (duration, humidity, temperature) and to the same degree of hydration to the concrete in question. Each mixture type needs its set of reference standards that spans the widest range of w/c ratio possible to ensure that determinations are reliable. However, this is difficult to duplicate for unknown concretes, and inevitably, there will be variations between the reference concretes used by some labs and the tested specimens. Indeed, this was noted by several participants of this study as a source of error.

Conventional concretes often contain supplementary cementitious materials (SCMs) and/or chemical admixtures, the presence of which will add to the uncertainty in the measurement of w/c ratio. For example, the relationship between w/c ratio, microstructure and microporosity, and hence fluorescence intensity may change with these additions and as the concrete matures, especially for slow reacting SCMs. The presence of glassy translucent SCMs such as slag will also influence the observed fluorescence intensity [20]. Therefore, reference standards that contain the same additions at different ages should be made to enable comparison at similar maturity. Care must be taken with concretes containing very fine SCMs such as microsilica because of the difficulty in detecting these materials with optical microscopy.
This also means that in many situations it would not be possible to rely wholly on fluorescence intensity without taking into consideration the many factors that can interfere with the relationship between microstructure and w/c ratio. For these reasons, it is usually necessary to consider other indicators of w/c ratio such as those listed in Table 3.

Whilst it is possible to perform a visual assessment of w/c ratio without the use of reference standards (e.g. Lab 01), such approach is highly subjective and relies entirely on the skills and experience of the petrographer. Similarly, the reliance on published images or data from the literature for comparison (e.g. Labs 02 , 08,13 ) is not considered satisfactory. Our data show that the largest errors occurred in labs that estimated w/c ratio visually without the use of proper reference standards. Excluding these labs will improve the overall accuracy of the optical test methods. Therefore, the standard-less approach is not recommended and it should be treated with caution. The availability of suitable reference standards that are similar to the specimen being tested is essential to the accuracy of the optical petrographic test method.

\subsection{Other factors influencing $\mathrm{w} / \mathrm{c}$ ratio determination}

There are potential sources of error unrelated to the concrete that can affect measurement of w/c ratio by fluorescence microscopy, many of which can be mitigated by technicians and petrographers skilled in the preparation and examination of thin sections. Possible errors include variation in the quality of impregnation with fluorescent resin; variation in size (thickness) of the thin section; accidental or partial removal of the fluorescent resin-impregnated zone during preparation; and variation in thin section of the test specimen compared to that of reference standards. Other potential errors are summarised in Table 3.

Related to this is the round-robin study by Jakobsen and Brown [31] to determine the reproducibility of the NT 361-1999 [9] fluorescence method. This involved 7 experienced petrographers to evaluate 29 thin sections from 6 field concretes. All petrographers used the same set of reference standards (w/c: $0.35-0.70$ at 0.05 interval). The estimated w/c ratio ranged from 0.3 to 0.8 . Accuracy was not determined because the true w/c ratios were unknown. However, they reported standard deviations between 0.01 and 
0.06 , which are remarkably consistent with this study. The authors [31] attributed the variation in the estimated w/c ratio to the variation in thickness and quality of the thin-sections, and carbonation that occurred during storage.

Another important factor is that the relationship between fluorescence intensity and apparent microporosity in thin sections becomes much less linear at the extremes. The reasons for this are that at very low w/c ratios the fluorescence levels become much harder to detect. It is also difficult to be confident that complete epoxy impregnation has been achieved and preserved in the polished sections [19, 32, 33]. At very high w/c ratios, the fluorescence becomes saturated and this makes it increasingly difficult to detect differences in microporosity. Furthermore, self-quenching of the fluorophores can occur, which reduces fluorescence intensity. To avoid this, the concentration of fluorescein dye could be reduced for very porous samples (which would also be required in the reference standards) [33]. All participants of this study used a constant dye concentration in their specimens.

As noted earlier, the optical petrographic methods have a strong tendency to over-estimate w/c ratio. There is a systematic trend for VA and FM-V to overestimate by $\sim 10 \%$ for the entire range of $0.35-0.55$ (Table 5). The FM-Q method, in contrast gave lower errors at $\mathrm{w} / \mathrm{c}$ ratios $\leq 0.40(\sim 1 \%)$ and much higher errors at $w / c$ ratios $\geq 0.50(\sim 20 \%)$. The overestimation occurs to a greater extent at high w/c ratios, possibly due to saturation and self-quenching of the fluorophores. A related issue is that fluorescence intensity decreases with light exposure and so reference standards will degrade with usage over time. This is compounded by the possibility that the test specimens are young (28-day cured) relative to the reference standards. In commercial laboratories, reference standards tend to be made of mature concretes where the hydration of cement is virtually as complete as possible so that they are more compatible to real structures.

Degree of cement hydration was measured by Lab 11 using the BSE method [21, 22] and this gave 0.77, $0.85,0.86,0.89$ and 0.91 for the w/c 0.35, 0.40, 0.45, 0.50 and 0.55 specimens respectively. The degree of hydration increased with increase in w/c ratio as expected and consistent with previous data. But these values are less than the ultimate degree of hydration expected from thermodynamic modelling or Powers' model [34, 35] so the specimens have potential to hydrate further. At equal w/c ratio, cement paste with lower degree of hydration contains higher porosity and so appears brighter in fluorescence imaging. Therefore, VA, FM-V and FM-Q will over-estimate w/c ratio if the references are more mature than the test specimens or if degraded (aged) references are used to compare against freshly prepared thin-sections.

In contrast, the BSE method underestimates (by up to $9 \%$ ) at high w/c ratios. This tendency has been reported in earlier studies [21,22]. This could be partly because the method measures free water and is sensitive to small amounts lost to bleeding and evaporation prior to hardening. Concretes with higher w/c ratio bleed more and this creates larger discrepancies between the estimated and expected w/c ratio. Bleeding effects tend to be more marked close to concrete surfaces and the small size of the prisms means that the specimens examined are never far away from a cast or trowelled surface. This may be another factor in the non-uniformity of the mixes that would influence all microscopy methods. Unfortunately, the actual amount of water lost to bleeding and evaporation is unknown. But a mass loss of only $7 \mathrm{~g}$ per prism is sufficient to decrease free $w / c$ by 0.01 . This is likely to be more problematic for lab specimens because of the larger exposed surface area per volume compared to real structures.

\subsection{Practical significance and future work}

This was the largest round-robin study of its type ever undertaken and represents the most extensive data collection available to-date. Nevertheless, it is important that we acknowledge its limitations. In particular, the limited number of specimens tested, which are "simple" concrete mixes containing no admixtures or mineral additions, and these laboratory prepared small-scale specimens do not fully reflect typical modern concretes. Consequently, the findings from this round-robin study are valid for these specimens only and extrapolation to other concrete mixes should be treated with caution.

Participants were given the flexibility to apply their preferred routine in-house methodology so that a wide range of methods currently in use were included to increase the robustness of the assessment. However, this meant that within each group (VA, FM-V, FM-Q), there were variations in the methodology and types of 
information provided by participants so it would not be appropriate to derive rigorous precision statistics such as repeatability or reproducibility for a particular method based on the collected data. It is also worth noting that the test specimens had w/c ratio varying at a fixed interval of 0.05 with other mix parameters constant. Participants received all five sub-specimens at the same time and so the exercise of ranking and estimating w/c ratio would seem relatively more straightforward compared to actual petrographic investigations of field concretes.

One of the outcomes of this study is that it would form a useful basis for future larger and more in-depth studies. Clearly, more work is needed to evaluate the microscopy methods on a greater number of mixes to better reflect current and emerging concrete technology, in particular concretes containing SCMs and other admixtures. A wider range of w/c ratios should be tested, especially at the higher end $(>0.55)$ that is usually of interest in the context of petrographic investigation for compliance and dispute resolution. However, the tendency for biases and errors at high w/c ratios needs careful consideration; for example, this may require increasing fines content to control bleeding. Another approach is to core samples from larger test specimens to mitigate variation in mix water dispersion caused by compaction and bleeding effects.

This study has shown that the best performing labs were able to estimate w/c ratio with consistent low errors. Further work is currently being planned to replicate these successful methods more widely in other labs to ascertain whether the good performance is achievable on a routine basis. Future trials will be carried out on these selected methods with rigorous statistical appraisal to determine their accuracy and precision.

\section{Conclusions}

A round-robin assessment of microscopy techniques for determining the water/cement ratio of hardened concrete has been completed. This involved 11 laboratories analysing five CEM I concrete mixes with w/c ratios (unknown to participants) of 0.35 , $0.40,0.45,0.50$ and 0.55 . Four techniques were evaluated: visual assessment of paste characteristics (VA), visual comparison of fluorescent intensity (FM-
V), quantitative assessment of fluorescent intensity (FM-Q) and quantitative backscattered electron microscopy (BSE). In total, 100 individual determinations of $w / c$ ratio were obtained, representing the largest study of its type ever reported. The main findings are:

(a) $37 \%$ of the estimated w/c ratios are within \pm 0.025 of the target mix values, $58 \%$ come to within \pm 0.05 and $81 \%$ are within \pm 0.1 . Errors in the estimated w/c ratios ranged from -0.058 to +0.23 or from $-14 \%$ to $+43 \%$ of the mix values.

(b) Statistical analysis show that 73 of the 80 data pairs were correctly ordered. 14 out of 20 sets of w/c ratio estimates from 7 labs gave the exact correct order of mix w/c ratios from low to high (A, C, E, B, D).

(c) Performance of individual labs was variable, with average error (w/c ratio) ranging from as low as $0.01-0.15$. Four participants performed consistently well across with low errors for all specimens. These were Labs 07 (VA + FM-V), 14b (VA), 05 (FM-Q), 14a (FM-Q) and 11 (BSE), with errors no greater than 0.05 .

(d) Optical microscopy-based methods have a tendency to over-estimate w/c ratio. VA and FM-V tended to over-estimate by $\sim 10 \%$ while FM-Q showed increasing error with increase in w/c ratio (up to $\sim 20 \%$ ). In contrast, the $\mathrm{BSE}$ method under-estimates (by up to $9 \%$ ) at high $\mathrm{w} / \mathrm{c}$ ratios.

(e) The largest errors occurred in labs that carried out visual assessment (VA, FM-V) without proper reference standards. Therefore, a qualitative standard-less approach is not recommended. The use of reference standards is essential for optical microscopy-based methods.

(f) Microscopy techniques produced much lower errors compared to the BS 1881-124 physicochemical method reported in Concrete Society inter-laboratory precision trial [3]. Within the optical petrographic methods (VA, FM-V, FMQ), labs that used reference standards performed better than those that did not. The BSE method gave the lowest range and average error.

In summary, microscopy techniques can provide meaningful information of the mix composition and accurate estimates of the $\mathrm{w} / \mathrm{c}$ ratio of hardened 
concrete. Further work is ongoing to test these methods on a wider range of contemporary concrete mixes and w/c ratios, and to determine their accuracy and precision.

Acknowledgements We would like to thank the Engineering Group of the Geological Society UK for their support. We particularly wish to thank Mr Michael Thomas (Tarmac Ready Mix Technical Centre, Lutterworth) for preparing the test specimens, Dr Ian Heritage (The Concrete Society) for witnessing the specimen preparation and all laboratories that have participated in this round-robin trial. We thank members of the Applied Petrography Group for their input and comments.

\section{Compliance with ethical standards}

Conflict of interest The authors declare that they have no conflict of interest.

Open Access This article is licensed under a Creative Commons Attribution 4.0 International License, which permits use, sharing, adaptation, distribution and reproduction in any medium or format, as long as you give appropriate credit to the original author(s) and the source, provide a link to the Creative Commons licence, and indicate if changes were made. The images or other third party material in this article are included in the article's Creative Commons licence, unless indicated otherwise in a credit line to the material. If material is not included in the article's Creative Commons licence and your intended use is not permitted by statutory regulation or exceeds the permitted use, you will need to obtain permission directly from the copyright holder. To view a copy of this licence, visit http://creativecommons.org/licenses/by/4.0/.

\section{References}

1. BS 1881-124 (2015) Testing concrete. Part 124: methods for analysis of hardened concrete. British Standards Institution, London

2. Concrete Society Technical Report TR 71 (2010) Concrete petrography: an introductory guide for the non-specialist. The Concrete Society, Camberley

3. Concrete Society Technical Report 32 (2014) Analysis of hardened concrete, 2nd edn. The Concrete Society, Camberley, Surrey

4. Poole AB, Sims I (2016) Concrete petrography: a handbook of investigative techniques, 2nd edn. CRC Press, London

5. Barnes R, Ingham J (2013) The chemical analysis of hardened concrete: results of a round robin trial, part 1 . Concrete Magazine, pp. 45-48, Oct

6. Barnes R, Ingham J (2013/2014) The chemical analysis of hardened concrete: results of a round robin trial, part 2 . Concrete Magazine, pp. 48-51, Dec/Jan

7. Ingham J, Barnes R (2015) Briefing: testing times for concrete structures-is BS 1881-124 still fit for purpose? Proc Inst Civ Eng Constr Mater 168(6):253-258
8. ASTM C856-11 (2011) Standard practice for the petrographic examination of hardened concrete. ASTM International

9. Build NT (1999) 361-1999 concrete, hardened: water-cement ratio. Nordtest method, Nordic Innovations Centre, Oslo

10. APG Special Report 2 (2010) A code of practice for the petrographic examination of concrete. Applied Petrography Group, London

11. BS 1881-211:(2016) Testing concrete. Part 211: procedure and terminology for the petrographic examination of hardened concrete. BSI Standards, London

12. Ingham J (2010) Geomaterials under the microscope: a colour guide. Manson, London

13. Walker HN, Lane DS, Stutzman PE (2006) Petrographic methods of examining hardened concrete: a petrographic manual, revised 2004. Virginia Transportation Research Council, Charlottesville

14. Christensen P, Gudmundsson H, Thaulow N, DamgardJensen AD, Chatterji S (1979) Structural and ingredient analysis of concrete-methods, results and experience. Nord Betong 3:4-9

15. Thaulow N, Damgard-Jensen AD, Chatterji S, Christensen $\mathrm{P}$, Gudmundsson H (1982) Estimation of the compressive strength of concrete samples by means of fluorescence microscopy. Nord Betong 26:2-4

16. Jakobsen UH, Laugesen P, Thaulow N (1999) Determination of water-cement ratio in hardened concrete by optical fluorescence microscopy. ACI Spec Publ 191:27-41. https://doi.org/10.14359/5732

17. Mayfield B (1990) The quantitative evaluation of the water/ cement ratio using fluorescence microscopy. Mag Concr Res 42(150):45-49. https://doi.org/10.1680/macr.1990.42. 150.45

18. Elsen J, Lens N, Aarre T, Quenard D, Smolej V (1995) Determination of the wc ratio of hardened cement paste and concrete samples on thin sections using automated image analysis techniques. Cem Concr Res 25(4):827-834. https:// doi.org/10.1016/0008-8846(95)00073-L

19. Jakobsen UH, Johansen V, Thaulow N (1995) Estimating the capillary porosity of cement paste by fluorescence microscopy and image analysis. In: Materials research society symposium-proceedings, pp 227-236

20. Sibbick RG, LaFleur C, Garrity S (2019) Using fluorescent microscopy as a tool in the determination of water to cementitious binder ratios in hardened concrete samples. ASTM Int. https://doi.org/10.1520/STP161320170235

21. Wong HS, Buenfeld NR (2009) Determining the watercement ratio, cement content, water content and degree of hydration of hardened cement paste: method development and validation on paste samples. Cem Concr Res 39(10):957-965. https://doi.org/10.1016/j.cemconres.2009. 06.013

22. Wong HS, Matter K, Buenfeld NR (2013) Estimating the original cement content and water-cement ratio of Portland cement concrete and mortar using backscattered electron microscopy. Mag Concr Res 65(11):693-706. https://doi. org/10.1680/macr.12.00201

23. Yio MHN, Phelan JC, Wong HS, Buenfeld NR (2014) Determining the slag fraction, water/binder ratio and degree of hydration in hardened cement pastes. Cem Concr Res 
56:171-181. https://doi.org/10.1016/j.cemconres.2013.12. 002

24. Neville A (2003) How closely can we determine the watercement ratio of hardened concrete? Mater Struct 36(5):311-318. https://doi.org/10.1007/bf02480870

25. Neville A (2006) Concrete: Neville's insights and issues. Thomas Telford, London

26. Erlin B (2002) A citation too far. Concr Int 24:14-16

27. Erlin B (2008) Catching the elusive water-cement ratio using petrographic methods and their evaluation. J ASTM Int 5(7):1-6. https://doi.org/10.1520/JAI100718

28. Scrivener KL, Crumbie AK, Laugesen P (2004) The interfacial transition zone (ITZ) between cement paste and aggregate in concrete. Interface Sci 12(4):411-421. https:// doi.org/10.1023/B:INTS.0000042339.92990.4c

29. Wong HS, Buenfeld NR (2006) Euclidean distance mapping for computing microstructural gradients at interfaces in composite materials. Cem Concr Res 36(6):1091-1097. https://doi.org/10.1016/j.cemconres.2005.10.003

30. Yio MHN, Wong HS, Buenfeld NR (2017) Representative elementary volume (REV) of cementitious materials from three-dimensional pore structure analysis. Cem Concr Res. https://doi.org/10.1016/j.cemconres.2017.09.012
31. Jakobsen UH, Brown DR (2006) Reproducibility of w/c ratio determination from fluorescent impregnated thin sections. Cem Concr Res 36(8):1567-1573. https://doi.org/10. 1016/j.cemconres.2006.05.003

32. Wong HS, Buenfeld NR (2006) Patch microstructure in cement-based materials: fact or artefact? Cem Concr Res 36(5):990-997. https://doi.org/10.1016/j.cemconres.2006. 02.008

33. St. John DA (1994) The use of fluorescent dyes and stains in the petrographic examination of concrete. The New Zealand Institute for Industrial Research and Development, Lower Hutt

34. Brouwers H (2005) The work of powers and brownyard revisited: part 2. Cem Concr Res 35(10):1922-1936

35. Powers TC, Brownyard TL (1947) Studies of the physical properties of hardened Portland cement paste, Bull 22, Research Lab of Portland Cement Association, Skokie. Reprinted from J Am Concr Inst (Proc) 43:101-249

Publisher's Note Springer Nature remains neutral with regard to jurisdictional claims in published maps and institutional affiliations. 